\title{
Privileging participation in the Pacific: Researcher reflections
}

\author{
Kate Saxton, Australian Catholic University, Brisbane, Australia
}

\begin{abstract}
This researcher reflection examines the challenges faced in using participatory action research (PAR) as a methodology when researching social work in Fiji. PAR allows for disadvantaged groups to engage in research and social action as a means to address inequity. However, PAR relies on people's ability and desire to participate in this process of change. The epistemological roots of PAR are well suited to Western notions of democracy and power, conflicting with how society operates within Fiji. This reflection examines some of the challenges faced in conducting PAR due to this cultural clash. In conducting this research, the researcher was forced to engage in deep and, at times, confronting, reflections about identity and positionality as both a critical social worker and researcher. By using a PAR approach as the starting point for research design and implementation, the research not only failed to empower Fijian social workers but at times replicated a form of neo-colonialism.
\end{abstract}

KEYWORDS: participatory action research; neocolonialism; social work research; Pacific Islands; Indigenous; cross-cultural practice

Social science research in Pacific Island communities has often been guilty of researching on, not with communities (Pacific Health Research Council [PHRC], 2003). Early ethnographic and anthological studies have positioned those in the Pacific as exotic or otherworldly, leading to a range of observational studies or research designed to help those less fortunate. Pacific Islander world views have been seen to be lacking in scientific knowledge and adding limited validity to social science research (Faleolo, 2013). Social and political sciences have maintained the idea of expert social researchers which can be seen through the extensive use of outside consultants and researchers in international aid and development projects in the Pacific Islands. This has led to local people's ideas being viewed as invalid as they might be untrained in the theories and methods of conventional social science, thus devaluing the contributions to both the form and the substance of a social research process
(Greenwood \& Levin, 2007; Trevithick, 2012). Sadly, this privileging of Western epistemological thought contributes to a cross-cultural research context where the Western researcher examines the experience of non-Western participants (Farrelly \& Nabobo-Baba, 2014; Tamasese, Peturu, Waldegrave, \& Bush, 2005). This approach fails to appreciate the nuances of the local context or to produce research that is not meaningful, appropriate and culturally viable for non-Western community contexts (Vaka, Brannelly, \& Huntington, 2016). From my own experience, this viewpoint highlights the ideological tensions within cross-cultural social work research, particularly when the impetus to draw on Western epistemology remains. It is written from my perspective as a kai valangi (white person) engaged in doctoral research focusing on Fijian experiences of social work. This reflection examines some of the complexities I faced as a white researcher
AOTEAROA NEW ZEALAND SOCIAL WORK 30(4), 9-12.

CORRESPONDENCE TO: Kate Saxton kate.saxton@acu.edu.au 
engaging in participatory action research (PAR) in Fiji.

I am a white, young, Australian woman with qualifications in both social work and international development. Coming from an academic environment I accept debate and the pursuit of knowledge to be normal and desirable goals. As a social worker I align myself with critical approaches that seek to address structural oppression and disadvantage. I reject the rhetoric of capacity building that positions many Pacific Island nations as deficit and lacking agency which only outside help can provide. I instead seek to work with, and alongside, communities in addressing structures of disadvantage that contribute to social marginalisation and hardship. I am overtly aware of the role both colonisation and globalisation play in the perpetuation of structural oppression and I cannot separate myself from potentially representing both these forces. And, whilst I recognise the epistemological positioning of critical social work may privilege Western constructions of social justice, I am grateful to the critical paradigm for supporting me to engage in reflective practice and research that questions the power and validity of Western influence within Pacific-based social work.

My exposure to, and interest in, social work within the Pacific Islands began when I was offered an AusAID-funded position to teach social work in Tonga. This sparked interest into what I observe as the international (read Western) agenda within the spread of social work education. From Tonga I came to live and work in Fiji and, at the time of my PhD research, I taught social work at the University of the South Pacific. Although I had some insider knowledge of Fijian culture, I was still firmly an expatriate and was paid a disproportionate salary compared to many of my local social work colleagues. Despite personal awareness of the privilege my positionality gave to me as a white researcher and academic, I soon discovered Western ideas proliferated in my work. This was a confronting notion - I considered myself an inclusive and culturally mindful individual. My attempts to engage with PAR both illustrate my well-meaning attempts to be inclusive and my blind-sightedness at the role of white privilege in cross-cultural research spaces.

To facilitate locally owned and meaningful research, I was attracted to the idea of PAR. PAR has found growing popularity globally and has demonstrated successes with diverse cultural groups researching social and community issues (McIntyre, 2008). For PAR to be truly participatory, it needs to operate on the principles of democratic participation, cooperation and empowerment. It can also be a cyclical process that needs to provide participants with the opportunity to review and critique the research process and it has a strong focus on reflexivity (MacKenzie, Tan, Hoverman, \& Baldwin, 2012). For me, engaging in PAR seemed ideal as the principles of collaboration and democracy not only aligned with my own critical social work value base, but I also believed that local Fijian constituents would take ownership of the project and see the value of social research. What I failed to recognise is that PAR aligned well with my epistemological positioning, but failed to acknowledge the cultural nuances which underpin Fijian daily living.

Historically, social research has not been accorded high priority in the Pacific region (Pryor, Finau, \& Tukuitonga, 2000). This is largely due to an inference that the pursuit of social knowledge is an intellectual luxury, in contrast to tangible outcomes which are clearly linked to the here and now of dayto-day survival (Finau, 1995). This has led to Pacific researchers and academics being perceived by Pacific communities as an "elite group" (PRHC, 2003). Many Pacific Island communities are disengaged from research generation limiting the recording of culturally informed knowledge and innovation.

Research that has been conducted is often underutilised due to the divergence of social needs and misunderstandings between the researcher and the researched (Finau, 1995). Once again, the process of being researched 
on rather than with has limited the application of social research in the Pacific Islands.

Colonisation has had an overwhelming influence on Fiji, including on the research process. As identified, my presence as a Western academic has inescapable connotations regarding how power and relationships were constructed. While the visible, physical acts of colonisation have not been pursued in Fiji for the past half century, the cultural and linguistic domination of Western philosophies has been in full force (Ravulo, 2016). The onset of globalisation has also seen a shift in the Fijian social landscape. With rapid urbanisation and a perceived increase in social issues, traditional family care and support networks have been eroded as the impetus for material and financial growth increases (Lockwood, 2003). This is a country that relies heavily on tourism and foreign aid to support basic health care and infrastructure. There is unspoken tension between the desire to resist foreign influence on one hand, and a financial overreliance on the other. As a social researcher, the distinctions between Western and Pacific identities became apparent, alongside existing tensions which hindered the ability to form collaborative understandings of social work that draw on both Pacific and Western ideologies (Ravulo, 2016).

Apart from failing to adequately recognise the colonial legacy in Fiji, I also did not fully appreciate the divergence between my own cultural values and Fijian community members in relation to participation. Whilst I was committed to the principles and process of PAR, I struggled to meaningfully engage with local social workers, who would often say "yes" to meetings and then not attend, or ask me prior to the interviews what it was I needed them to say. At that time, driven by my own research agenda and ideological push for democracy, I failed to acknowledge the hierarchical structure of traditional Fijian society, which is clan based and patriarchal. PAR also asks participants to be critical and actively review processes and evaluate content. This overt engagement with critical thought is a stark divergence from the lived experience of education in Fiji, where rote learning and the legacy of colonialism encourage students to obey authority and maintain the status quo (Tuinamuana, 2007). In my experience, "not rocking the boat" remained at the forefront of decision-making processes for many research participants. This on-the-ground reality was at odds with my vision for PAR; a vision predicated by my critical framework, driven by a commitment to social change. Because of my desire to avoid researching on, I was blindsided by my potential to reinforce foreign epistemological research practices that might be counter-cultural to traditional Fijian values and ways of knowing, being and doing. In short, I was running the gauntlet of the intellectual neo-colonialism which I so fervently strived to avoid.

In my attempts to conduct PAR, I also failed to properly account for the sociohistorical context, in which Fiji was being governed by a military regime and has multiple experiences of coups and political instability (Trnka, 2008). While I am attracted to democratic principles and equal participation, such an attraction seems rooted in my white Western privilege and upbringing where I have been able to freely participate in political life and personal decision-making. Additionally, one aim of critical research is increased political engagement, brought about by raising the level of participant consciousness thus empowering people to act to change existing social structures and processes (Bloomberg \& Volpe, 2012). An outsider in this context, it would have been easy for me to encourage a critical agenda within social work. However, this fails to acknowledge my Western privilege - being able to draw on my Australian citizenship status and the freedoms of travel, financial and legal resources. And my critical ideological approach could actually risk the safety and wellbeing of local Fijians. To be confronted with my own cultural ignorance in this way was challenging. This is especially so when I espouse a school of critical thought that 
demands I acknowledge my own position and remain vigilant in situations where dominant discourse runs the risk of oppressing and marginalising the views of others.

If we are to honour cultural needs within diverse social work contexts, we need to appreciate how health, wellbeing and positive social care are defined, understood and experienced in Fiji (Kee, Martin, \& Ow, 2014). This is paramount when Fijian worldviews differ from the prevailing, usually Western, constructions of health and wellbeing (Vaka et al., 2016). Correlated to this, if we are to facilitate effective cross-cultural research and response to Pacific issues, the use of traditional cultural epistemologies and processes becomes vital (Ravulo, 2016). Too often in social research, certain types of knowledge are privileged over others. In constructing paradigms of what constitutes social work by drawing on mainstream Western theory, social work marginalizes indigenous and local knowledge and engages in what Ravulo (2016, p. 191) refers to as "intellectual colonisation." In this manner, globalised notions of social work deny the very diversity and cultural dynamism they seek to celebrate. Whilst the importance and recognition of indigenous and subjugated knowledge has increased in recent years, this does not always carry as much perceived validity as the expert knowledge of professionals. There is a risk that Indigenous and local Pacific knowledge will be discounted or considered less relevant (Farrelly \& Nabobo-Baba, 2014). My own experience illustrates how difficult it can be to ensure a non-colonial research position and process despite best intentions. As social workers and researchers we must continue to examine our own positions when working cross-culturally and develop much deeper, more nuanced understandings of terms such as participation. Finding culturally appropriate ways of working and researching in the Pacific Islands is deserving of more attention, creativity and reciprocity. I will continue to strive for new ways to engage, conceptualise and understand my role as a kai valangi and social researcher and attempt to learn from past mistakes.

\section{References}

Bloomberg, L. D., \& Volpe, M. (2012). Competing your qualitative dissertation: $A$ road map from beginning to end (2nd ed.). Thousand Oaks, CA: Sage.

Faleolo, M. (2013). Authentication in social work education: The balancing act. In C. Noble, M. Hendrickson, \& I. Y. Han (Eds.), Social work education: Voices from the Asia Pacific (2nd ed., pp. 149-172). Sydney, NSW: University of Sydney Press.

Farrelly, T., \& Nabobo-Baba, U. (2014). Talanoa as empathic apprenticeship. Asia Pacific Viewpoint, 55(3), 319-330. doi:10.1111/apv.12060

Finau, S. A. (1995). Health research in the Pacific: In search of a reality. New Zealand Medical Journal, 108, 16-19.

Greenwood, D. J., \& Levin, M. (2007). Introduction to action research (2nd ed.). Thousand Oaks, CA: Sage.

Kee, L. H., Martin, J., \& Ow, R. (2014). Cross-cultural social work: local and global. South Yarra, VIC: MacMillan Education Australia.

Lockwood, V. (2003). Globalization and culture change in the Pacific Islands. Boston, MA: Pearson Education.

Mackenzie, J., Tan, P. H., Hoverman, S., \& Baldwin, C. (2012). The value and limitations of participatory action research methodology. Journal of Hydrology, 474, 11-21. doi:10.1016/j.jhydrol.2012.09.008

McIntyre, A. (2008). Participatory action research. Thousand Oaks, CA: Sage Publications.

Pacific Health Research Council (PRHC). (2003). Pacificentric health research methods. Anthology Series No.1, Suva, Fiji: Fiji School of Medicine.

Pryor, J., Finau, S., \& Tukuitonga, C. (2000). Pacific Health Research Council: Health research by and for Pacificans. Pacific Health Dialogue, 7, 115-117.

Ravulo, J. (2016). Pacific epistemologies in professional social work practice, policy and research. Asia Pacific Journal of Social Work and Development, 26, 191-202. doi:1080/02185385.2016.1234970

Tamasese, K., Peturu, C., Waldegrave, C., \& Bush, A. (2005). Ole Taeao Afua, the new morning: A qualitative investigation into Samoan perspectives on mental health and culturally appropriate services. Australian and New Zealand Journal of Psychiatry, 39, 300-309. doi:10.1080/j.1440-1614.2005.01572.x

Trevithick, P. (2012). Social work skills and knowledge: A practice handbook (3rd ed.). Maidenhead, UK: Open University Press.

Trnka, S. (2008). State of suffering: Political violence and community survival in Fiji. Ithaca, NY: Cornell University Press.

Tuinamuana, K. (2007). Reconstructing dominant paradigms of teacher education: Possibilities for pedagogical transformation in Fiji. Asia-Pacific Journal of Teacher Education, 35, 111-127. doi:10.1080/13598660701268544

Vaka, S., Brannelly, T., \& Huntington, A. (2016). Getting to the heart of the story: Using talanoa to explore Pacific mental health. Issues in Mental Health Nursing, 37(8), 537-544. doi:10.1080/01612840.2016.1186253 